\title{
Analysis of Intra-Day Volatility under Economic Crisis Conditions
}

\author{
Michalis Glezakos \\ Department of Insurance and Statistics, University of Piraeus \\ 80 Karaoli \& Dimitriou, 185 34, Piraeus, Greece \\ E-mail: migl@unipi.gr \\ Konstantinos Vafiadis \\ Bank of Greece \\ 4 Ag. Stefanou, Neapolis, 56727, Thessalonica, Greece \\ E-mail:kvafiadis@bankofgreece.gr; kostasbaf@yahoo.com \\ John Mylonakis (Corresponding Author) \\ 10, Nikiforou str., Glyfada, 166 75, Athens, Greece \\ E-mail: imylonakis@vodafone.net.gr
}

Received: February 10, 2011

Accepted: February 24, 2011

doi:10.5539/ijef.v3n4p60

\begin{abstract}
The purpose of this paper is to examine intra-day volatility of the Athens (GI), Frankfurt (DAX) and New York (DJ) Stock Markets under conditions of economic crisis. After utilizing 5 minutes intervals of the periods September December of 2008 and 2009, a U-shaped intra-day volatility pattern was observed for DJ and an L-shaped one for DAX and GI. The results indicate a sharp spike in the first 30 minutes and some weaker spikes for the rest of the trading. Moreover, the influence of the New York Stock market to the European markets was dominant. At the same time, GI and DAX exhibited a significantly positive correlation, particularly in last quarter of 2008. Finally, volatility of returns was unusually high in 2008 , obviously due to the prevailing global financial crisis.
\end{abstract}

Keywords: Intra-day volatility, Stock markets, Economic crisis

\section{Introduction}

Share price volatility creates huge risks, as well as, huge earnings opportunities, so it is of interest to both academics and business experts. As a result, numerous studies have tried to identify volatility patterns, as well as, their relationship to several economic and market parameters, such as the phase of the real economy (recession, recovery, growth) and the maturity of the stock markets or their timing (developing or developed stock markets, upwards or downwards movements).

Initially, volatility was analyzed by using daily data. However, the development of computer hardware and software permitted the data bases' creators to record transaction prices within the stock exchanges trading. As a result, it is possible now to study intraday prices, thus enriching the evidence about their distributional properties and their volatility patterns.

The present study is focused on the analysis of the intraday volatility of the major Indices of the following three Stock Exchange markets:

- New York Stock Exchange (DJ), as the worldwide leading stock market,

- Frankfurt Stock Exchange (DAX), as the leading European stock market, and the

- Athens Stock Exchange (GI), as a developed market showing strong characteristics of a developing market in the Balkan region.

The results of this study contribute to the identification of possible similarities and differences between the intra-day volatility patterns of the developed and the developing markets. Also, they provide evidence regarding the effect of the current economic crisis on intra-day volatility behavior. 


\section{Past Literature}

Intra-day volatility was analyzed for first time by Prince (1982) who studied hourly prices of a sample of shares included in the DJ Index, for the period 1960-64. Few years later, Wood et al. (1985) utilized share prices in the New York Stock Exchange (NYSE) with time interval of one minute. They concluded that intra-day volatility followed a U shaped pattern. However, their finding was not confirmed by the subsequent study of Harris (1986) who analysed data of the same market, using a 15 minutes interval. Lockwood and Linn (1990) provided, also, support evidence of the findings of Wood et al. (1985) by analyzing hourly prices of the DJ Index, for the period 1964-1969.

The U-shaped pattern was, also, identified by the works of Hong and Wang (2000), Cheung et al. (1994), Cheung (1995), Bildik (2001), Copeland and Jones (2002) - Korea, Wood, McInish and Ord (1985), Jain and Joh (1988), Foster and Viswanathan (1993), Kleidon and Werner (1996), Abhyankar et al (1994), Hong and Wang (2000) and Ozenbas et al.(2002).

The U-shaped pattern of the intra-day volatility was further explored by Lam and Tong (1999) who found that the U shape was formed by the volatility of the first and the last half hour trading periods of the studied stock exchange trading. Their findings were confirmed by Ozenbas et al. (2002) some years later.

Other studies provided evidence that the peak at the beginning of the stock exchange trading was often very strong, as opposed to a weak peak at the end of the trading, suggesting that an L shaped pattern could better describe the behavior of the intraday volatility. The L shaped pattern was mainly supported by the studies of Fleming and Remolona (1999) for the USA market, Gary Tian and Mingyuan Guo (2007) and Fei Ren et al (2008) for the Chinese market, Jeffrey Williams and James Eaves (2007) for the Japanese market and Roberto Pascual and David Veredas (2009) for Spanish market.

Similar findings were provided by Harju and Hussain (2006) who asserted that the European Indices FTSE 100, XDAX30, SMI and CAC40 followed a reverse J pattern which differed slightly to an L pattern. Also, Ozenbas (2006) asserted that the same was true for NASDAQ and NYSE, as well as, for the London Stock Exchange, the Deutsche Boerse and Euronext. In contrast to these findings, Syed Mujahid Hussain (2008) found a J shaped pattern in the DAX, for the period 2004-2005. As a conclusion, two patterns of the intraday volatility prevail in the relevant literature, the $\mathrm{U}$ and $\mathrm{L}$ ones.

A number of studies compared in parallel the intra-day volatility patterns which prevailed in the stock exchanges of several countries. Pagano and Roell (1991) kal Dejong, Nijman and Roell (1993) studied the Stock markets of Italy and France; Ozenbas et al. (2002) compared the markets of USA, UK, France and Germany while Werner and Kleidon (1996) focused their study on the stock markets of USA and UK. The above studies depicted that for a given time period, the patterns did not differ substantially from country to country. Moreover, it was found that the $\mathrm{U}$ and L shaped patterns could adequately describe the intra-day volatility in all sampled Stock markets.

One of the significant results of the global economic activity is that the developed stock markets affect each other instantaneously and increasingly. It is found that intra-day volatility patterns, independently of their shape, exhibit several "nails" during the daily stock market trading. This is particularly observed in the European stock markets which are seriously affected by are closely connected to Frankfurt Stock Exchange, as well as, by to NYSE. In this spirit, Roberto Pascual and David Veredas (2009), utilizing Spanish data, found that intraday volatility was better described by an L-shape pattern with a peak at the opening time of NYSE.

Identifying the relationship between Stock returns and volatility, Harris (1986) provided evidence that high (positive or negative) returns were recorded at the first and the last minutes of the trading. His findings were also consisted with the fundamentals of the financial theory, suggesting that, on average, high risks (that is high volatility) are associated by high returns. Similar results were proved by Blume et al. (1994), Handa and Schwartz (1996) and Weinberg and Steven (2001).

The positive relationship between volatility and marketability was, also, proved by Amihud and Mendelson (1987), Gerety and Mulherin (1994), Barber and Odean (2000), Stoll (2000) and Bessembinder and Rath (2008), while Hasbrouck and Schwartz (1988) and Werner and Kleidon (1996) found a similar relationship between volatility and transactions cost.

The majority of the above studies (Werner and Kleidon, 1996 and Wood, McInish and Ord, 1985) carried out intra-day volatility surveys based on the following assumptions:

- $\quad$ Each trading day was divided into distinct periods (= intervals) of 1,5 or 15 minutes and the return of each interval was calculated. 
- The returns which corresponded to interval $\mathrm{j}$ (for $\mathrm{j}=1$ it was the first interval) of each trading day in the sample were used for the calculation of the mean return and hence the standard deviation of this interval. So, for a number of $\mathrm{k}$ intervals, $\mathrm{k}$ standard deviations (SD) were calculated, expressing the volatility of the k distinct periods of every stock market trading day.

\section{Data and Methodology}

For the purposes of the present study, intra-day prices of DJ (NYSE), DAX (Frankfurt Stock Exchange) and GI (Athens Stock Exchange), for the periods 1-9-2008 to 31-12-2008 and 1-9-2009 to 31-12-2009 were recorded, by using 5 minutes intervals. The source of the above prices was the data base FOREKS FX2000.

Following the majority of the past studies (Wood, McInish and Ord, 1985, Harris, 1986, Lockwood and Linn, 1990, Ozenbas, Schwartz and Wood, 2002, Tian and Guo, 2007, Werner and Kleidon, 1996) intra-day volatility was calculated as follows:

- A stock market trading day was divided into intervals, of 5 minutes each.

- The return of each intra-day interval, for each index in the sample, was calculated according to the following equation:

$$
R_{k, i, j}=\ln \frac{P_{k, i, j}}{P_{k, i, j-1}}
$$

Where: $R_{k, i, j}=$ the return of the index $k$, for day $i$ and interval $j$ and $P_{k, i, j}=$ the price of index $k$, of the day $i$, of the interval $\mathrm{j}$.

- The mean value of all $R_{k, i \text { for }} j=1$ (that is $R_{k, i, 1}$ ), consists of the mean return of the first interval for each index $\left(\mathrm{m}_{\mathrm{k}, 1}\right)$ and their standard deviation consists of the corresponding volatility $\left(\sigma_{\mathrm{k}, 1}^{2}\right)$. For $\mathrm{Y}$ intervals and $\mathrm{N}$ transaction days, a number of $\mathrm{Y}$ means $\left(\mathrm{m}_{\mathrm{k}, \mathrm{j}}\right)$ and $\mathrm{Y}$ standard deviations $\left(\sigma_{\mathrm{k}, \mathrm{j}}\right)$ can be obtained :

$$
\begin{aligned}
m_{k, 1} & =\sum_{i=1}^{N} \frac{R_{k, i, 1}}{N}, \quad m_{k, 2}=\sum_{i=1}^{N} \frac{R_{k, i, 2}}{N}, \ldots \ldots \ldots, m_{k, Y}=\sum_{i=1}^{N} \frac{R_{k, i, L}}{N} \\
\sigma_{k, 1}^{2} & =\frac{1}{N}\left(R_{k, i, 1}-m_{k, 1}\right)^{2}, \quad \sigma_{k, 2}^{2}=\frac{1}{N}\left(R_{k, i, 2}-m_{k, 2}\right)^{2}, \ldots, \quad \sigma_{k, Y}^{2}=\frac{1}{N}\left(R_{k, i, L}-m_{k, l}\right)^{2} .
\end{aligned}
$$

- Normality of the return distributions was tested through Kolmogorov - Smirnov test.

- Correlation between the SDs of the indices of the sample, in pairs, was tested by Pearson Correlation Coefficient.

- For the interpretation of the observed volatility during the day, time differences among Athens, Frankfurt and New York were taken into account.

\section{Research and Interpretation of Results}

\subsection{Properties of the distributions of the intra-day returns}

It is well known that over the second half of 2007, a severe financial crisis took place in the USA that it was very quickly spread over Europe and Asia, given the strong interrelationships among the major world financial markets. Within one year, this crisis was transformed into a global economic crisis. Thus, the time period under study (2008-2009) coincided with the above crisis, permitting conclusions regarding intra-day volatility over such extreme world economic and financial circumstances.

Up to the end of 2008, the depth and duration of the above crisis were unobservable. Thus, the perceived uncertainty by investors was too high, shooting up the standard deviation of the Stock returns $(\mathrm{GI}=0,42, \mathrm{DAX}=0,43, \mathrm{DJ}=0,45)$. Meanwhile, several emergency liquidity plans were carried out in USA and Europe, channeling huge amounts of capital to the international financial system. At the end of the first of 2009, the accumulated evidence was suggestive that economies could return to positive rates of growth up to 2010-2011. In the light of such expectations, stock market overall volatility, as well as, intra-day volatility were considerably reduced (Table 1).

However, the Athens Stock Exchange was, in 2009, almost twice as volatile $(0,20)$, as the Stock markets of Frankfurt $(0,13)$ and New York $(0,10)$. The explanation is obvious: Although in 2008 all economies faced huge risks without any exception, in 2009 the strong ones were almost stabilized, contrary to the Greek economy which entered to a deeper structural crisis. 
During the period under review, the returns of the Indices examined were found symmetrically distributed around their mean, forming leptokurtic distributions. The lack of normality was, also, identified by the Garch analysis. The leptokurtic characteristic is the combined result of the great number of observations and the short time interval. Finally, the high values of the z-statistic of Kolmogorov-Smirnov, suggest that normality of the distributions of all three indices should be rejected (Table 1 and Histograms 1-6).

\subsection{Interactions among GI, DAX and DJ}

Applying Pearson test to the intra-day returns of the three indices in the sample, we find a statistically significant positive correlation between GI and DAX at 5\% level (Table 2). The findings of this study are in line with the conclusions of Glezakos et al. (2007) who found that the above two Indices were strongly interrelated over the period 2000-2006.

The same conclusion is reached from the visual inspection of the intra-day diagrams of the returns and the volatility of returns, for both periods 2008 and 2009 (Diagrams 1-2). It is obvious that the two indices followed an almost parallel path, during the daily stock exchange trading. More particularly, the intra-day volatility of both Stock markets consistently exhibited a sudden increase at 12.00 and 14.55 (Greenwich Time) in 2008 and at 12.30, 13.55 and 14.55 in 2009. This finding obviously suggests that the Greek and the German Stock markets are affected by the positive or negative flow of information through the Reuters or Bloomberg.

It is, also, obvious that the opening of the New York Stock Exchange affects the volatility of Frankfurt and Athens Stock markets. The findings are in line with Glezakos et al (2007), as well as, with Harju and Hussain (2006) who reached the same conclusion for the European indices FTSE 100, XDAX30, SMI and CAC40. The interrelationship among DJ, DAX and GI was, also, proved positive $(0,276)$ and statistically significant.

The intra-day volatility interactions of GI and DAX could be explained as follows:

$>$ According to the past literature, the corresponding Stock Exchanges are interrelated (Glezakos et al., 2007, Harju and Hussain, 2006).

$>$ The dominant world information providers, such as Reuters, Bloomberg, use to release certain information sets (world economic variables and indicators) at certain time periods. As a result, international investors revised their expectations at that time and reacted accordingly.

$>$ European investors adjusted their expectations the time of the DJ opening bell (Diagrams 3-4).

\subsection{Intra-day volatility patterns}

The intra-day volatility pattern of GI and DAX was of L-shape, revealing that volatility takes its higher price at the beginning of everyday trading (Diagrams 5-7). L-shaped patterns were, also, identified among others by Harris (1986), Deniz et al (2002), Lam and Tong (1999) and Tang and Lui (2002). On the contrary, Wood et al (1985), Harris (1986), Lockwood and Linn (1990), Werner and Kleidon (1996), Ozenbas, Schwartz and Wood (2002) suggested a U-shaped pattern for DAX.

Regarding DJ, the intra-day volatility is better expressed by a U-shaped pattern, as the following diagram reveals. Wood et al. (1985), Harris (1986), Lockwood and Linn (1990), Werner and Kleidon (1996), Ozenbas, Schwartz and Wood (2002), Harju and Hussain (2006), also, found a U-shape while Syed M. (2008) argued that if the first two observations are removed then the first peak disappears.

Past literature has suggested several explanations interpreting the identified intra-day volatility patterns. Initially, Amihud and Mendelson (1991) introduced the "overnight information effect" explaining the high volatility of the first minutes. They argued that numerous investment decisions, based on information which is accumulated between the closing time of day $t$ and the opening time of day $t+1$, were taken within the first seconds of the trading $t$, thus strongly affecting the volatility of the market (= the first "nail" of the U or L shape). Tian and Guo (2007) and Beny and Howe (1994) accepted the above explanation, stressing the effect of information on the intra-day volatility. Kyle (1985), Holden and Subrahmanyam (1992), as well as, Foster and Viswanathan (1993) have argued that market makers are responsible for the first nail, given that they introduced a great number of orders in the preopening as well as at the opening of the stock markets. Regarding last nail of the U shaped patterns, Ozenbas et al. (2002) found that it is mainly the result of the investors' effort to settle their short or long positions at the end of the stock trading.

Finally, the several peaks that were formed during the day, might be due to the peculiarities of the particular stock exchanges like transaction procedures (i.e. auctions, continuous trading, existence of market makers, etc), upper or lower price limits, opening / closing time and alike. 


\section{Conclusions}

The findings of this study provide support to earlier empirical works asserting that the world Stock markets are positively correlated. More particularly, the correlation of returns of GI and DAX was statistically significant at the last quarters of 2008 and 2009 while DJ exerted dominant influence upon both of them. Regarding the intra-day volatility patterns of GI and DAX, the analysis showed that they were L-shaped, while DJ's was U-shaped. The coincidence of the Stock markets in the sample is the result of the contemporaneous flow of information worldwide. Thus, investors' expectations and, consequently, their transactions were affected by the same set of information at the same time.

Also, the first "nail" of the intra-day volatility patterns was due to the incorporation of the accumulated information, prior to the market opening, in the first transactions of the trading day. In the case of the U-shaped patterns (like in the case of DJ), the last "nail" was mostly due to the instantaneous settlement of the investors' open positions.

Finally, the several peaks that were formed during the day might be due to the peculiarities of the particular Stock Exchange, like transaction procedures (auctions, continuous trading, existence of market makers etc), upper or lower price limits, as well as, opening / closing time. The provided evidence suggests that the interrelation of the world stock markets, as well as, the patterns of the intra-day volatility remain strong even in periods of severe world economic crisis.

\section{References}

Abhyankar, A. H., D. G., Levin, E. \& Limmack, R.J. (1994). Bid-Ask Spreads, Trading Activity and Trading Hours: Intraday Evidence from the London Stock Exchange. Journal of Business Finance and Accounting, 24(3/4), 343-362.

Amihud, Y. \& Mendelson, H. (1987). Trading Mechanisms and Stock Returns: An Empirical Investigation. Journal of Finance, 42, 533-553. doi:10.2307/2328369, http://dx.doi.org/10.2307/2328369

Andersen, T., Bollerslev, T. \& Das, A. (2001). Variance-ratio Statistics and High-frequency Data: Testing for Changes in Intraday Volatility Patterns. Journal of Finance, 56, 305-27. doi:10.1111/0022-1082.00326, http://dx.doi.org/10.1111/0022-1082.00326

Barber, B. \& Odean, T. (2000). Too many Cooks Spoil the Profits: Investment Club Performance. Financial Analyst Journal, January/February, 17-25. doi:10.2469/faj.v56.n1.2326, http://dx.doi.org/10.2469/faj.v56.n1.2326

Bessembinder, \& Rath, (2008). Does Market Structure Matter? Trading Costs and Return Volatility Around Exchange Listings. June, Curtin University of Technology

Bildik, R. (2001). Intra-day Seasonalities on Stock Returns: Evidence from the Turkish Stock Market. Emerging Markets Review, 2, 387-417. doi:10.1016/S1566-0141(01)00026-7, http://dx.doi.org/10.1016/S1566-0141(01)00026-7

Blume, L., Easley, D. \& O' Hara, M. (1994). Market Statistics and Technical Analysis: The Role of Volume. Journal of Finance, 49(1), 153-181. doi:10.2307/2329139, http://dx.doi.org/10.2307/2329139

Cheung, Y. (1995). Intraday Returns and the Day-end Effect: Evidence from the Hong Kong Equity Market. Journal of Business Finance and Accounting, October, 1023-1035 doi:10.1111/j.1468-5957.1995.tb00891.x, http://dx.doi.org/10.1111/j.1468-5957.1995.tb00891.x

Cheung, Y., L., Ho, R. Y.-ki, Poope, P. \& Draper, P. (1994). Intraday Stock Return Volatility: The Hong Kong Evidence. Pacific-Basin Finance Journal, 2, 261-276. doi:10.1016/0927-538X(94)90020-5, http://dx.doi.org/10.1016/0927-538X(94)90020-5

Copeland, L. \& Jones, S.A. (2002). Intradaily Patterns in the Korea Index Futures Market. Asian Econ Journal, 16(2), 153-174. doi:10.1111/1467-8381.00146, http://dx.doi.org/10.1111/1467-8381.00146

Dejong, F., Nijman, T. \& Roell, A. (1993). A Comparison of the Cost of Trading French Shares on the Paris Bourse and on SEAQ International. LSE Financial Markets Group Discussion Paper No. 169, London School of Economics

Eaves, J. \& Jeffrey, W. (2007). Walrasian tâtonnement auctions on the Tokyo Grain Exchange. Review of Financial Studies, 20, 1183-1218. doi:10.1093/revfin/hhm001, http://dx.doi.org/10.1093/revfin/hhm001

Fei, R. \& Wei-Xing, Z. (2008). Multiscaling Behavior in the Volatility Return Intervals of Chinese Indices. EPL, 84, 68001 doi:10.1209/0295-5075/84/68001, http://dx.doi.org/10.1209/0295-5075/84/68001

Fleming, M. J. \& Remolona, E. M. (1999). Price Formation and Liquidity in the U.S. Treasury Market: The Response to Public Information. Journal of Finance, 54(5), 1901-1915. doi:10.1111/0022-1082.00172, http://dx.doi.org/10.1111/0022-1082.00172 
Foster, F. D., \& Viswanathan, S. (1993). Variations in Trading Volume, Returns Volatility and Trading Costs: Evidence on Recent Price Formation Models. Journal of Finance, 48, 187-211 doi:10.2307/2328886, http://dx.doi.org/10.2307/2328886

Gerety, M. S. \& Mulherin, H. (1994). Price Formation on Stock Exchanges: The Evolution of Trading within the day. Review of Financial Studies, 7, 609-629. doi:10.1093/rfs/7.3.609, http://dx.doi.org/10.1093/rfs/7.3.609

Glezakos, M., Merika, A. \& Kaligosfiris, H. (2007). Interdependence of Major World Stock Exchanges: How is the Athens Stock Exchange Affected?. Journal of Finance and Economics, Issue 7, 24-39.

Handa, P. \& Schwartz, R. (1996). Limit Order Trading. The Journal of Finance, Vol. 51(5), 1835-1861. doi:10.2307/2329540, http://dx.doi.org/10.2307/2329540

Harju, K. \& Mujahid, H. S. (2006). Intraday Seasonalities and Macroeconomic News Announcements. Meddelanden Working Papers, 512

Harris, L. (1986). A Transaction Data Study of Weekly and Intradaily Patterns in Stock Returns. Journal of Financial Economics, 16, North-Holland, 99-117.

Hasbrouck, J. and Schwartz, R. A. (1988). Liquidity and Execution Costs in Equity Markets. Journal of Portfolio Management, Spring, 10-16. doi:10.3905/jpm.1988.409160, http://dx.doi.org/10.3905/jpm.1988.409160

Hong, H. and Wang J. (2000). Trading and Returns under Periodic Market Closures. Journal of Finance, February, Vol. LV, No. 1.

Jain, P.C. \& Joh, G.H. (1988). The Dependence between Hourly Prices and Trading Volume. Journal of Financial and Quantitative Analysis, 23, 269-283. doi:10.2307/2331067, http://dx.doi.org/10.2307/2331067

Lam, P. H.L. \& Tong, W. H.S. (1999). Interdaily Volatility in a Continuous Order-Driven Market. Journal of Business Finance and Accounting, 26, 7/8, 1013-1036. doi:10.1111/1468-5957.00284, http://dx.doi.org/10.1111/1468-5957.00284

Lockwood, L.J. \& Linn, S.C. (1990). An Examination of Stock Market Return Volatility During Overnight and Intraday Periods, 1964-1989. Journal of Finance, 45, 591-602. doi:10.2307/2328672, http://dx.doi.org/10.2307/2328672

Mujahid, H. S. (2008). The Intraday Behaviour of Bid-Ask Spreads, Trading Volume and Return Volatility: Evidence from XDAX30. Unpublished.

Ozenbas, D. (2006). Pattern of Short-term Volatility Accentuation within the Trading Day: An Investigation of the US and European Equity Markets. Business \& Economics Research Journal, 5(2), February

Ozenbas, D, Schwartz, R.A., \& Wood, R.A. (2002). Volatility in US and European equity markets: An Assessment of Market Quality. Journal of International Finance, 5(3), 437-461. doi:10.1111/1468-2362.00103, http://dx.doi.org/10.1111/1468-2362.00103

Pagano, M., \& Roell, A. (1991). Dually Traded Italian Equities: London vs. Milan. CEPR Discussion Paper, No. 564, London

Pascual, R. \& Veredas, D. (2009). Does the Open Limit Order Book Matter in Explaining Informational Volatility?. Journal of Financial Econometrics, 1-31.

Prince, P. (1982). Day of the week effects: Hourly data. Manuscript, University of Chicano, Chicago, IL

Stoll, H. R. (2000). Friction. Journal of Finance, 55, 1479 - 1514. doi:10.1111/0022-1082.00259, http://dx.doi.org/10.1111/0022-1082.00259

Tian, G. G. \& Guo, M. (2007). Interday and intraday volatility: Additional evidence from the Shanghai Stock Exchange. Review of Quantitative Financial Accounting, 28, 287-306. doi:10.1007/s11156-006-0011-x, http://dx.doi.org/10.1007/s11156-006-0011-x

Tang, G.Y. N. \& Lui, D. T. W. (2002). Intraday and Intraweek Volatility Patterns of Hang Seng Index and index futures and a test of the Wait-to-trade Hypothesis. Pacific-Basin Finance Journal, 10, 475-495. doi:10.1016/S0927-538X(02)00069-0, http://dx.doi.org/10.1016/S0927-538X(02)00069-0

Weinberg, S. A. (2001). Interpreting the volatility smile: An examination of the International content of Options Prices. International Finance Discussion Papers, No 706, Federal Reserve Board Washington, D.C.

Wood, R.A., Mc Inish, T. H., \& Ord, J. K. An Investigation of Transactions Data for NYSE Stocks. Journal of Finance, 40, 723-739. doi:10.2307/2327796, http://dx.doi.org/10.2307/2327796 
Table 1. Basic Statistics of the Distributions of the Intra-Day Returns

\begin{tabular}{|c|c|c|c|c|c|c|}
\hline & & Mean & $\begin{array}{l}\text { Standard } \\
\text { Deviation }\end{array}$ & $\begin{array}{c}\text { Skewness } \\
\text { (standard error) }\end{array}$ & $\begin{array}{c}\text { Kurtosis } \\
\text { (standard } \\
\text { error) }\end{array}$ & Kolmogorov- Smirnov Z \\
\hline GI & 2008 & $-0,102$ & 0,42024 & $\begin{array}{c}-0,444 \\
(0,037)\end{array}$ & $\begin{array}{r}150,88 \\
(0,073) \\
\end{array}$ & 12,415 \\
\hline DAX & 2008 & $-0,0013$ & 0,44946 & $\begin{array}{l}-1,482 \\
(0,041)\end{array}$ & $\begin{array}{l}76,790 \\
(0,082)\end{array}$ & 6,419 \\
\hline DJ & 2008 & $-0,0028$ & 0,43384 & $\begin{array}{l}-0,025 \\
(0,036) \\
\end{array}$ & $\begin{array}{l}16,534 \\
(0,073) \\
\end{array}$ & 5,726 \\
\hline GI & 2009 & $-0,0027$ & 0,20374 & $\begin{array}{l}-0,286 \\
(0,031)\end{array}$ & $\begin{array}{l}18,346 \\
(0,062)\end{array}$ & 9,729 \\
\hline DAX & 2009 & 0,0010 & 0,12791 & $\begin{array}{c}0,594 \\
(0,030) \\
\end{array}$ & $\begin{array}{l}24,644 \\
(0,059) \\
\end{array}$ & 9,560 \\
\hline DJ & 2009 & 0,017 & 0,10033 & $\begin{array}{c}0,309 \\
(0,031)\end{array}$ & $\begin{array}{l}16,445 \\
(0,062)\end{array}$ & 8,065 \\
\hline
\end{tabular}

Table 2. Pearson Correlation Coefficient

\begin{tabular}{|l|c|}
\hline & Mean return DAX 2008-2009 \\
\hline Mean return GI 2008-2009 & 0,276 \\
\hline Sig. (2-tailed) & \\
\hline \multicolumn{2}{|l|}{ Correlation is significant at the 0.05 level of significance (2-tailed) } \\
\hline
\end{tabular}

Histogram 1: GI (ASE) 2008

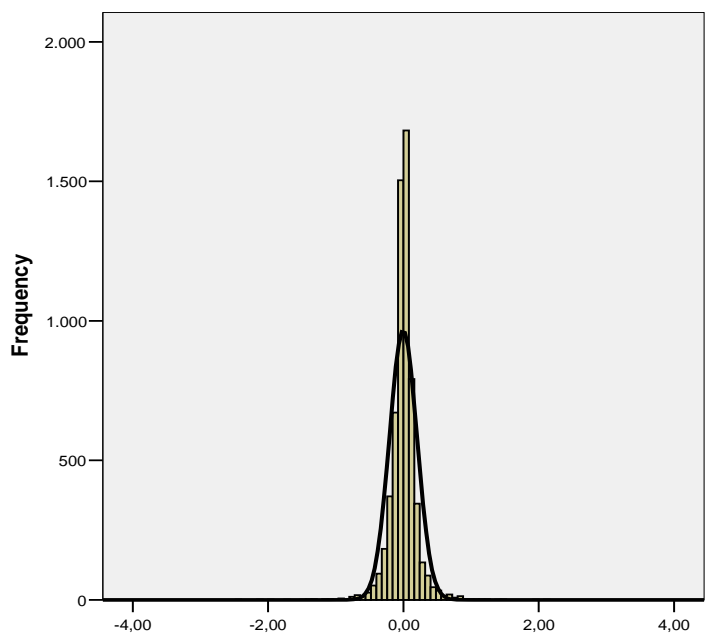

Histogram 2: GI (ASE) 2009

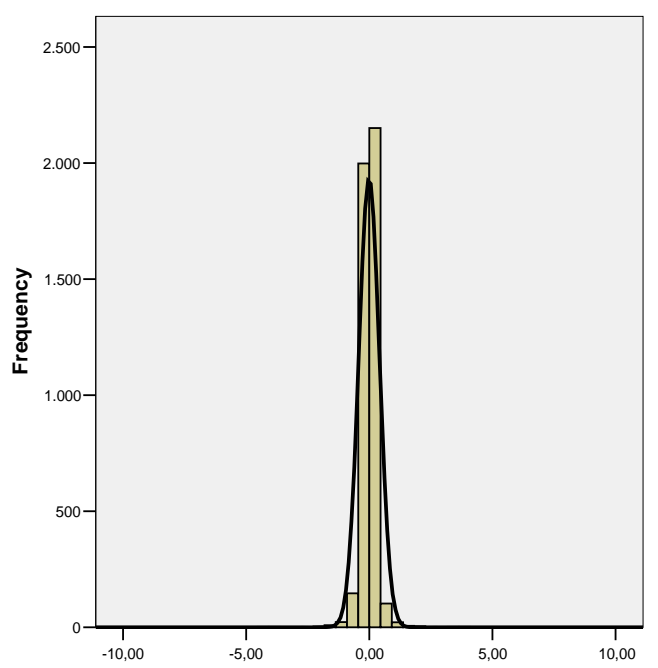


Histogram 3: DAX 2008

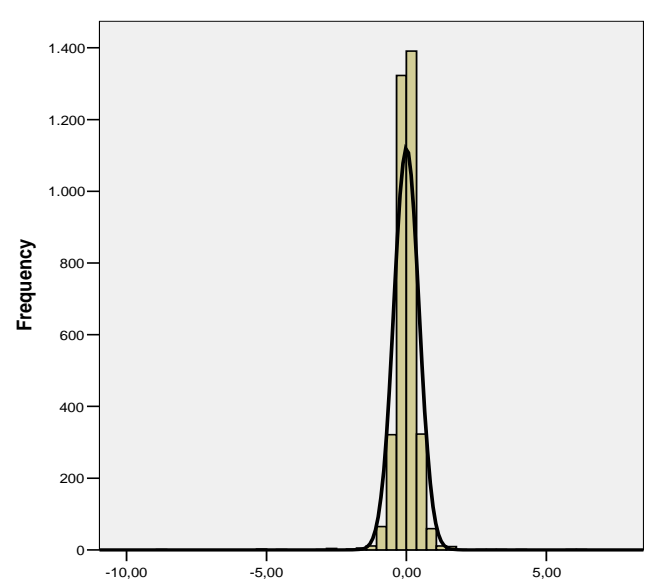

Histogram 5: DJ 2008

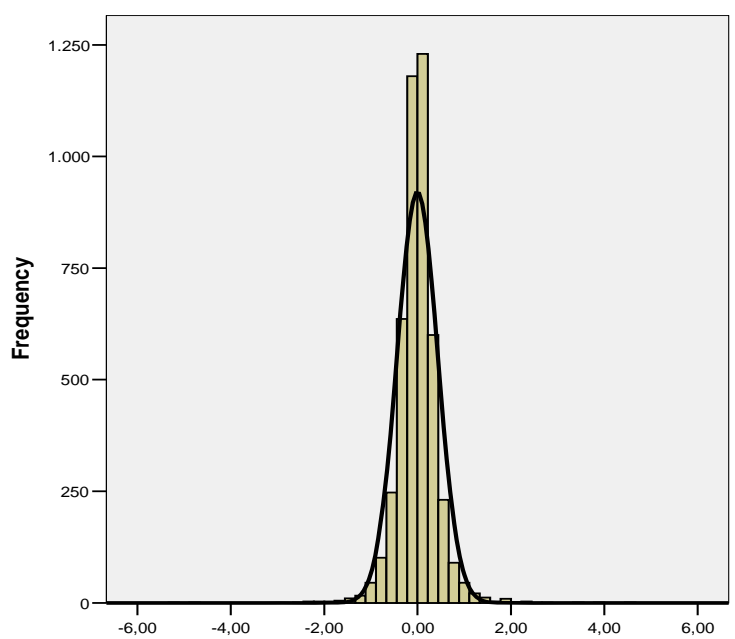

Histogram 4: DAX 2009

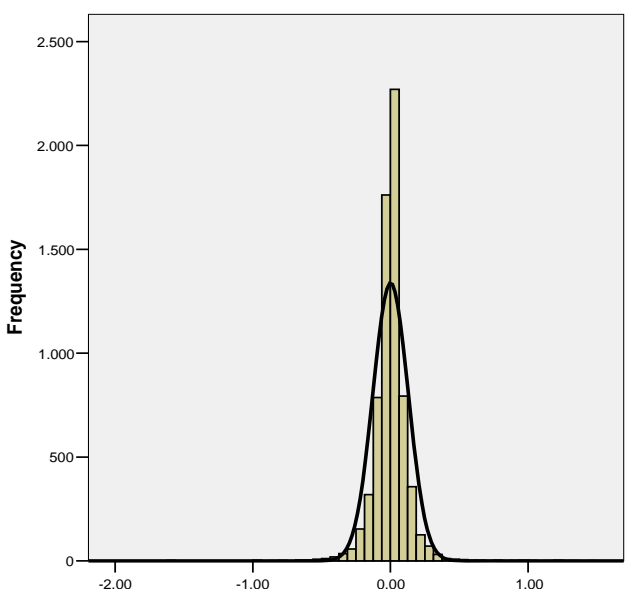

Histogram 6: DJ 2009

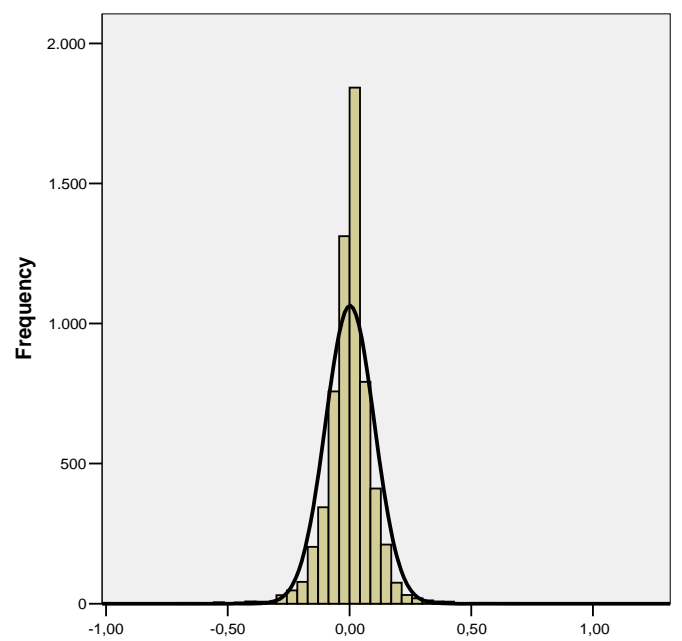

Diagram 1: Intra-Day Volatility patterns of DAX and GI, 2008

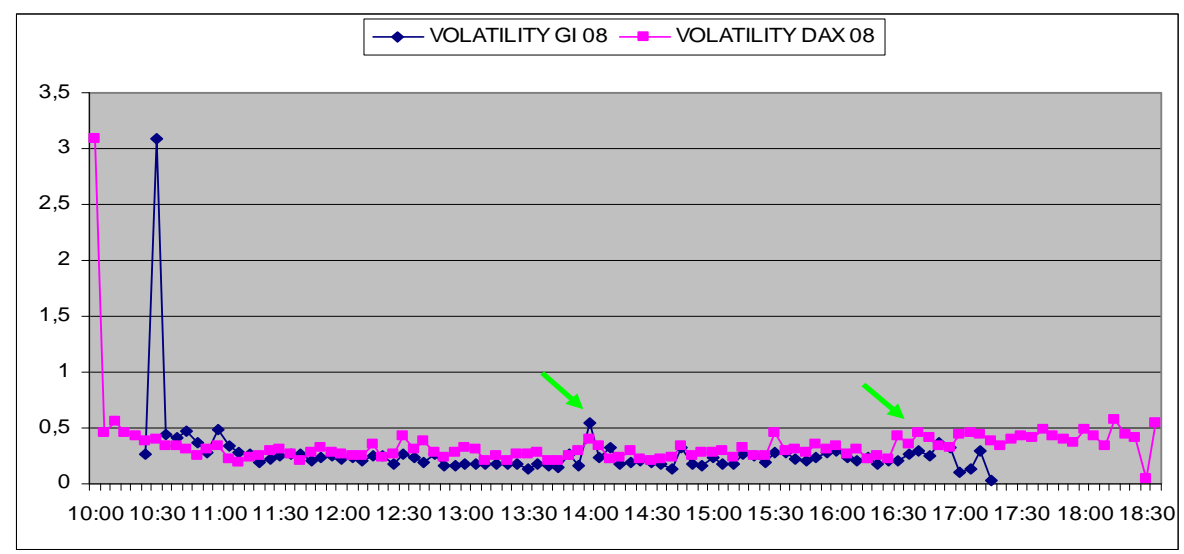


Diagram 2: Intra-Day Volatility patterns of DAX and GI, 2009

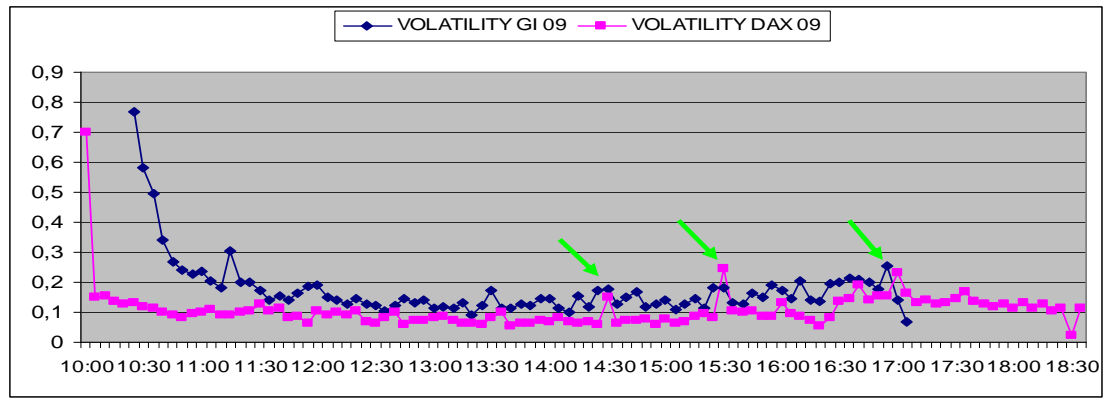

Diagram 3: Intra-Day Volatility patterns of DJ, DAX and GI, 2008

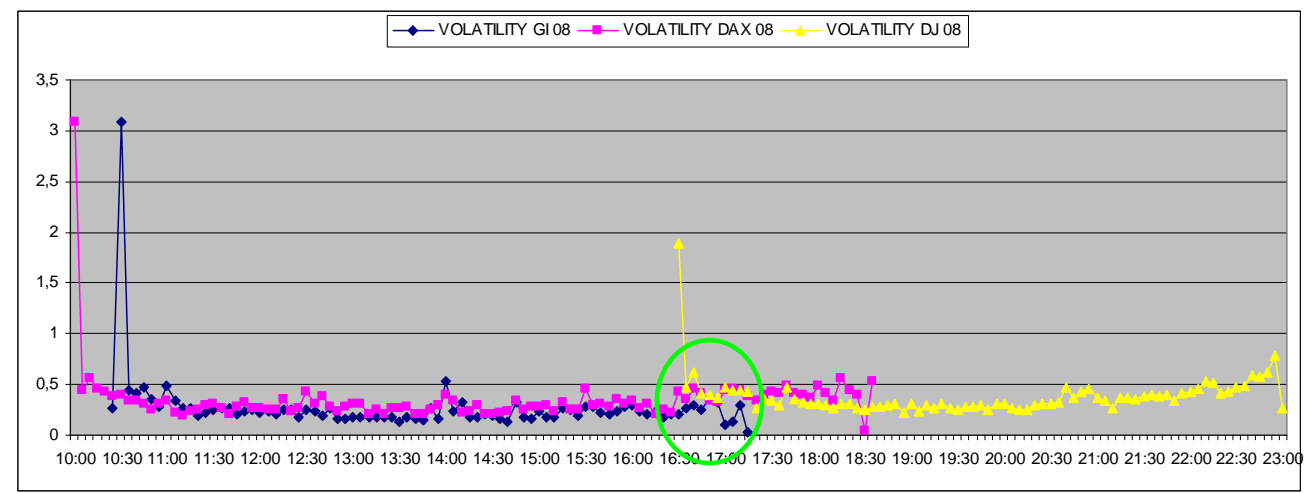

Diagram 4: Intra-Day Volatility patterns of DJ, DAX and GI, 2009

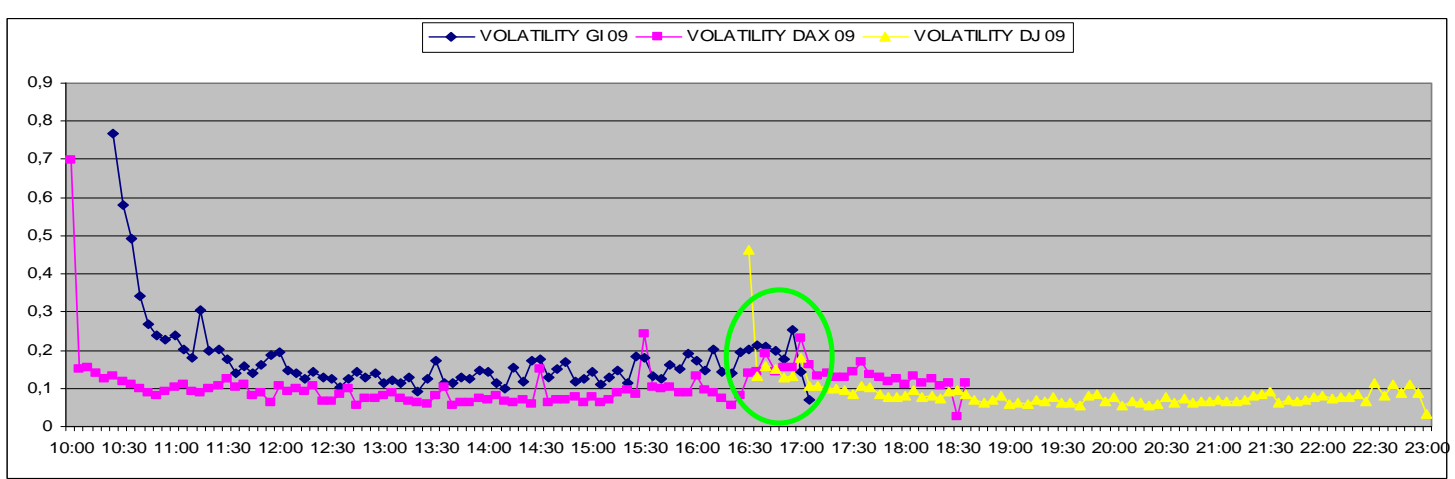

Diagram 5: Intra-Day Volatility patterns of GI

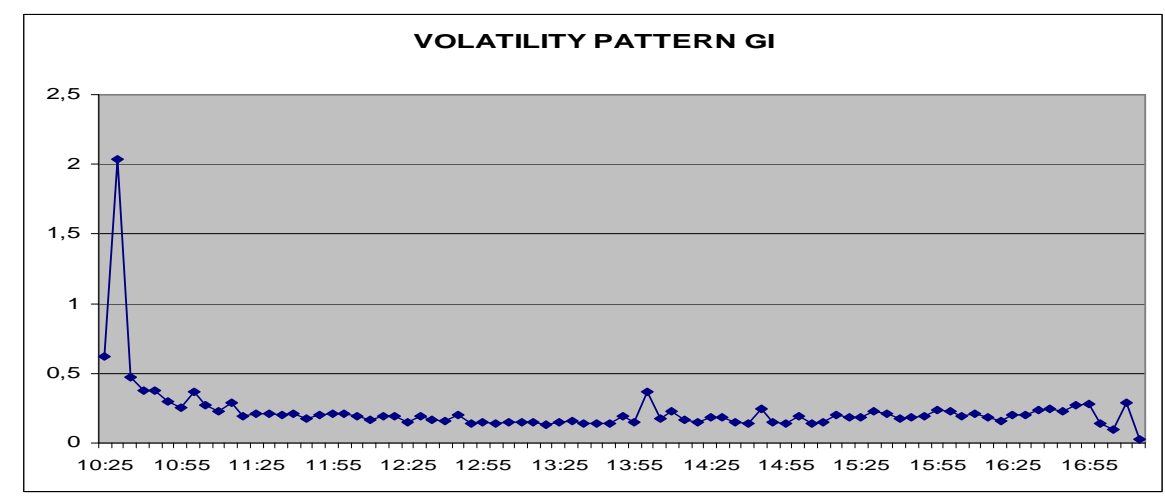


Diagram 6: Intra-Day Volatility patterns of DAX

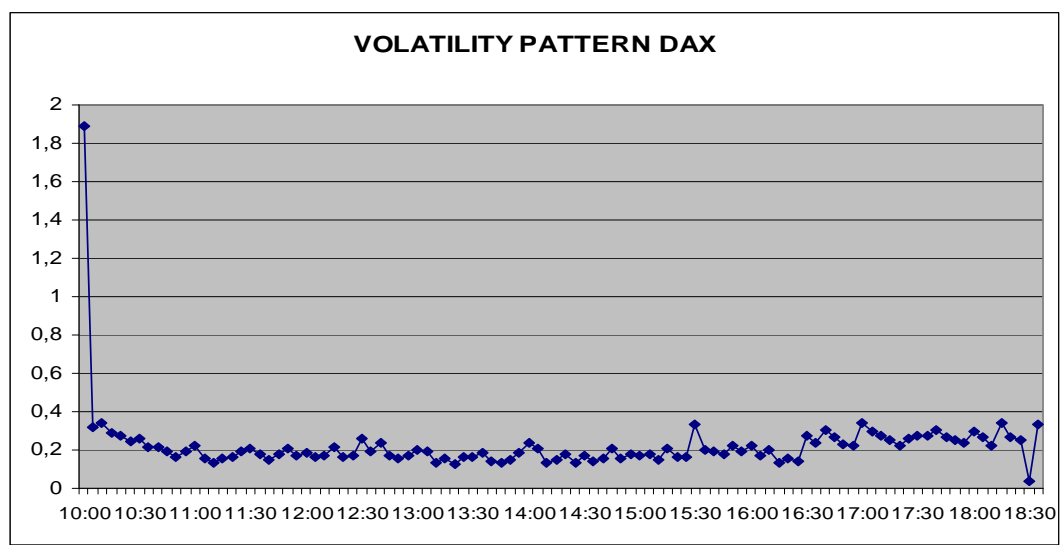

Diagram 7: Intra-Day Volatility patterns of DJ

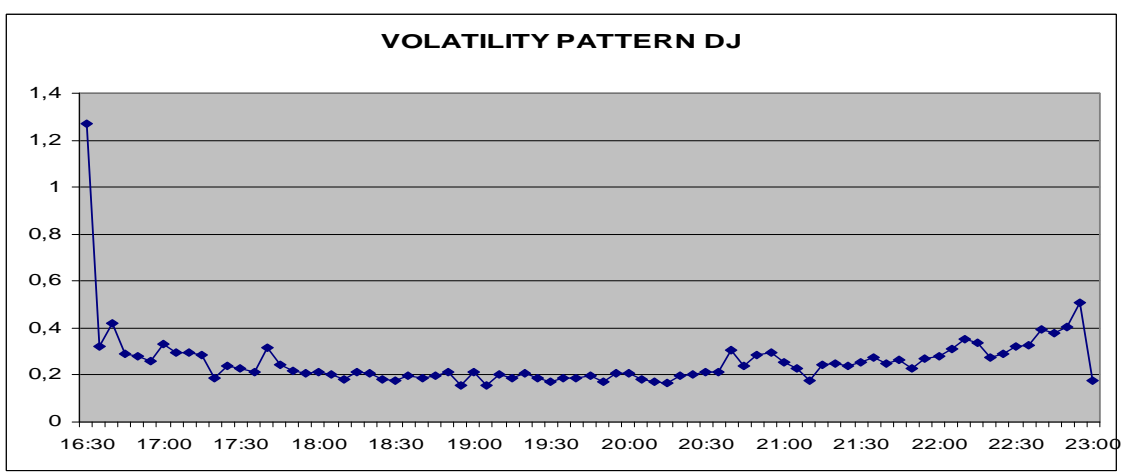

